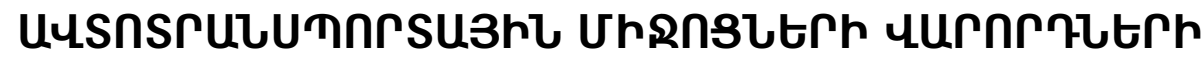

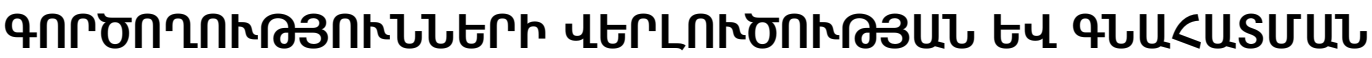

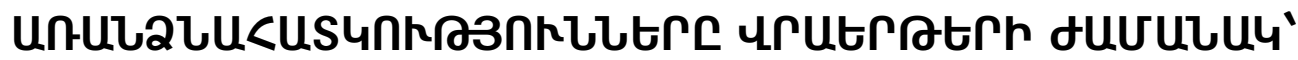

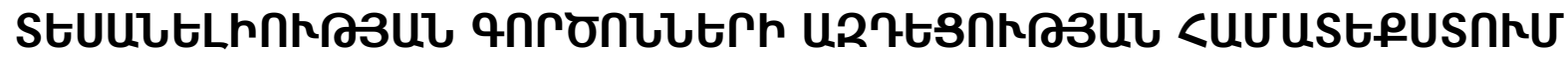

\author{
7.щцшрјшน 7.U.

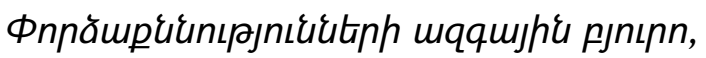 \\ tplumu, <mјшичмие
}

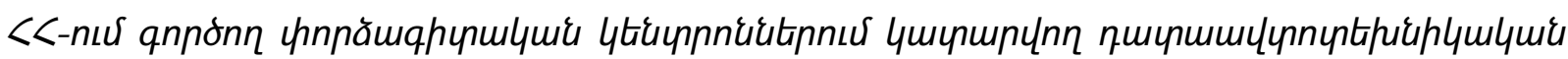

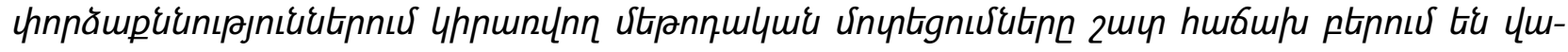

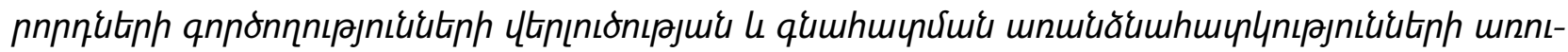
uny upuml htrulunspjnıkitiph:

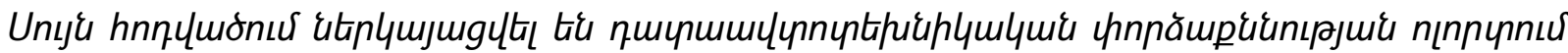

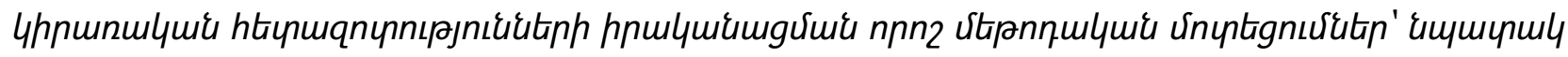

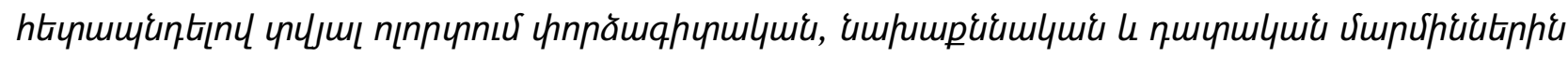

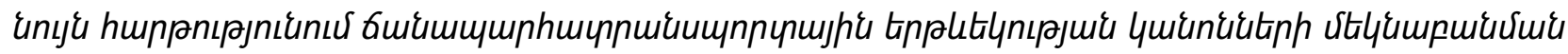

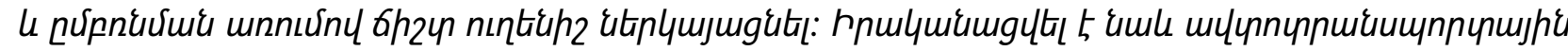

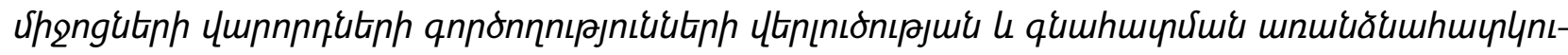
ponsuktinn unutipptiph duviukuly:

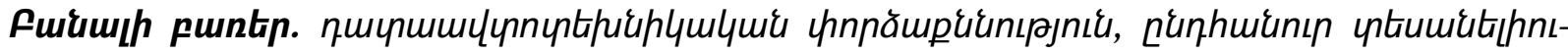

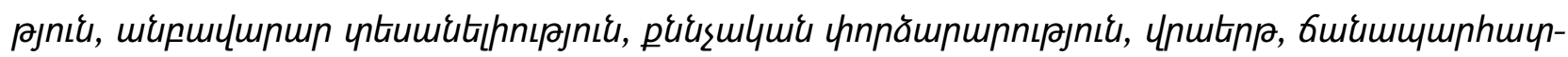

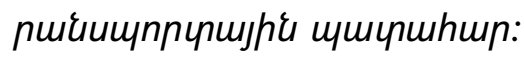

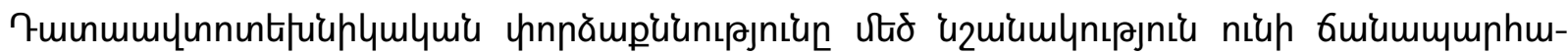

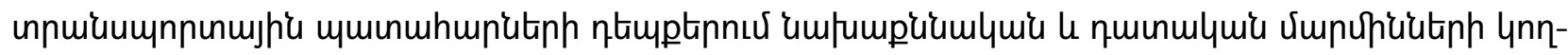

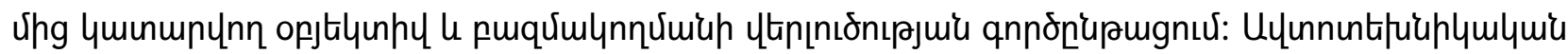

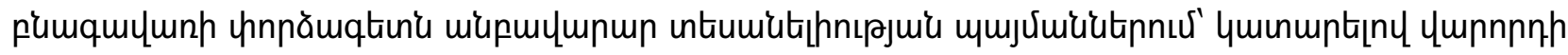

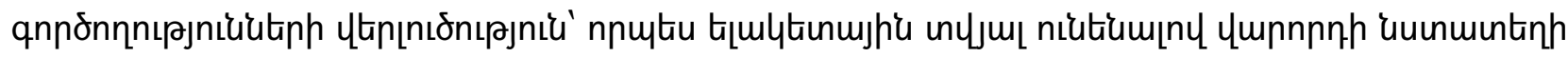

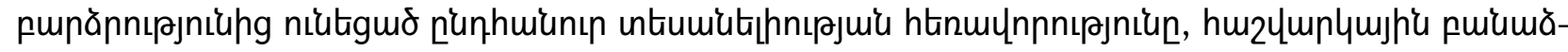

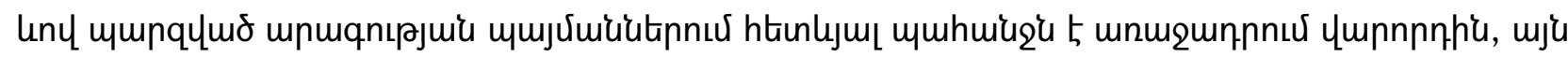

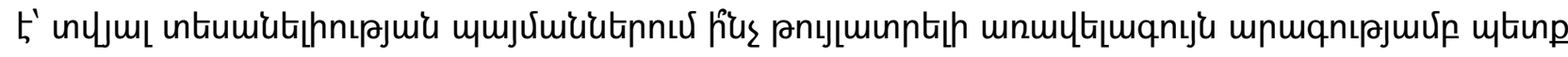

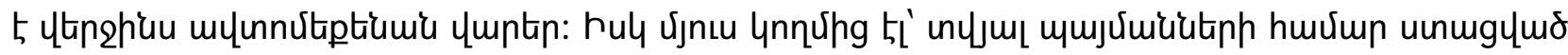

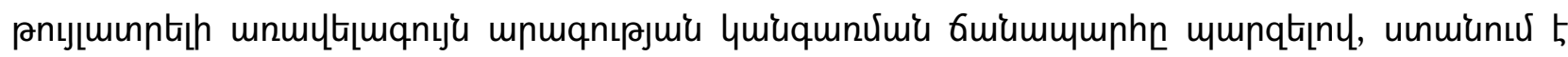

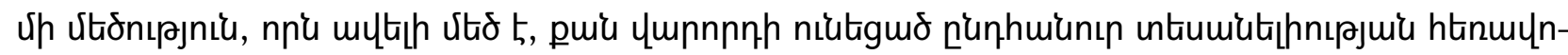

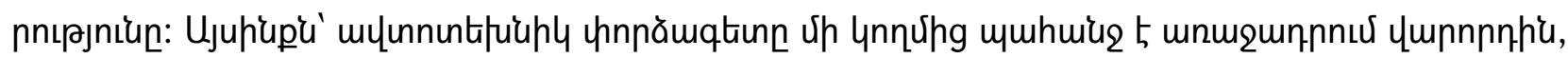

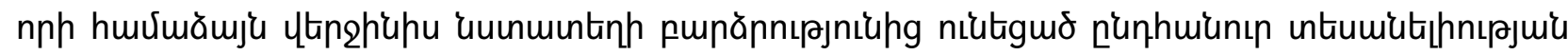

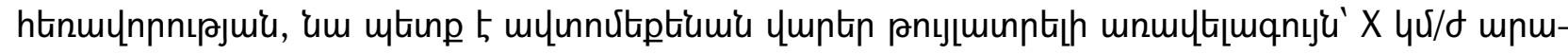

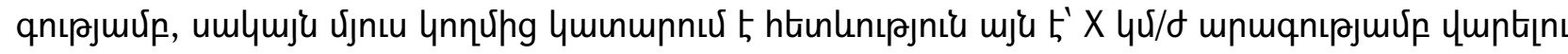

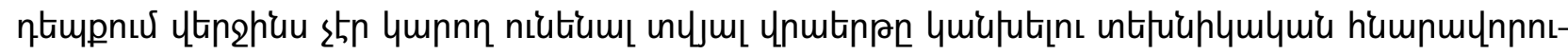

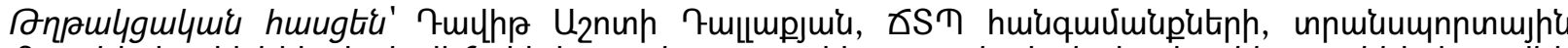

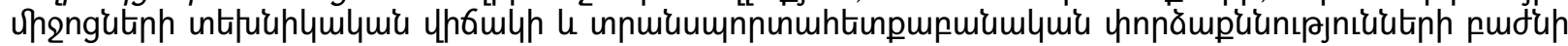

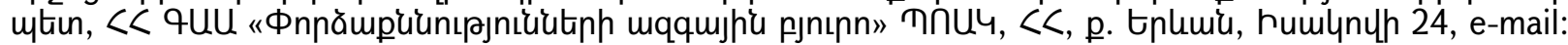
d.dallakyan@nbe.am 


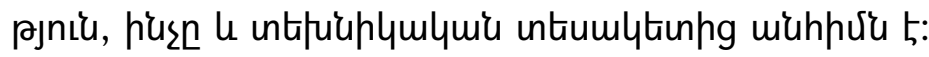

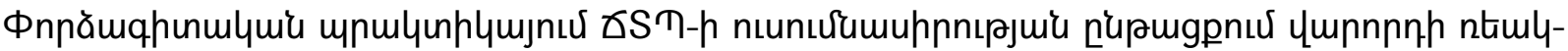

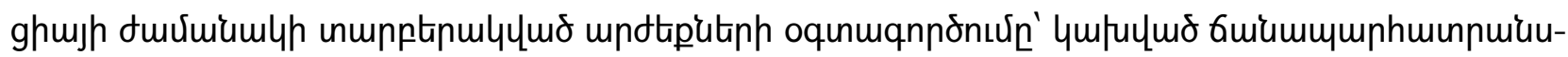

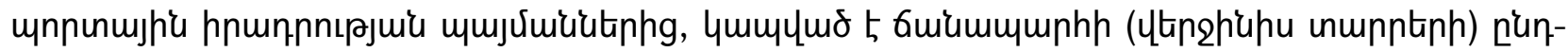

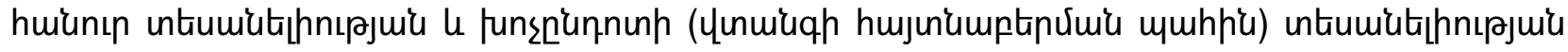

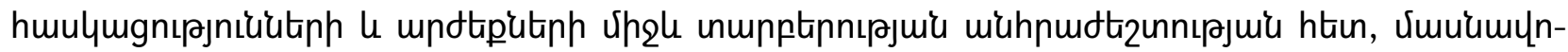

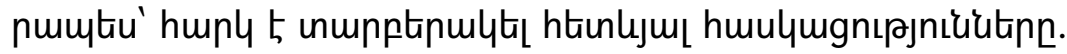

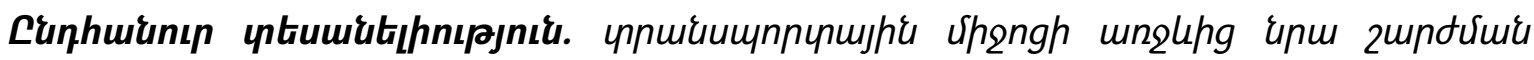

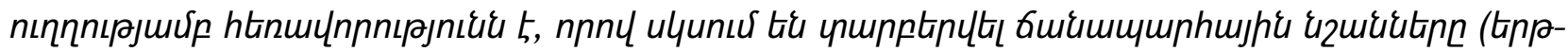

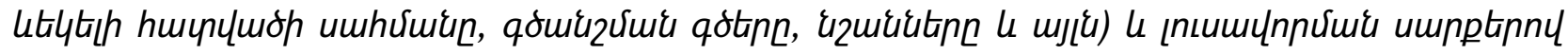

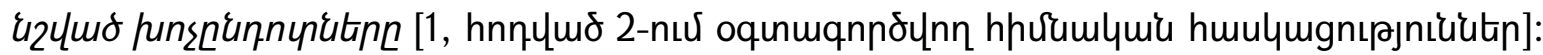

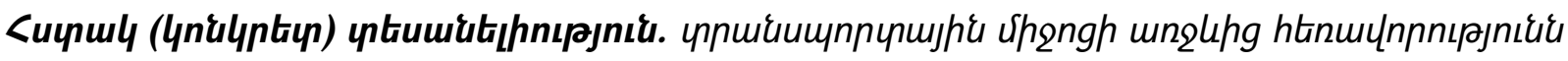

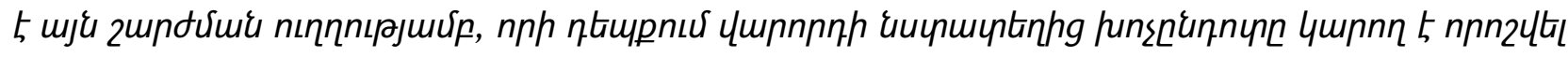

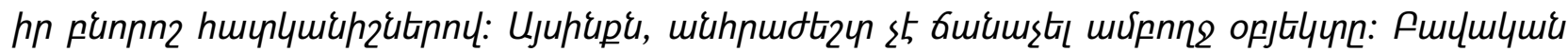

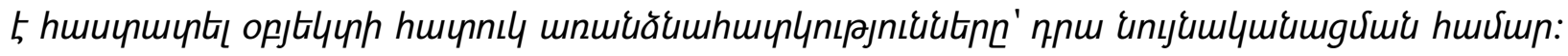

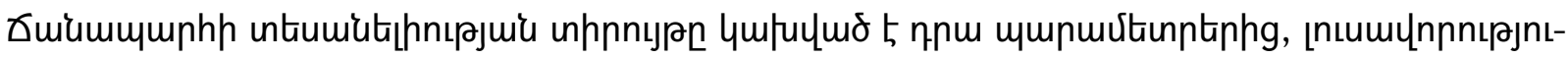

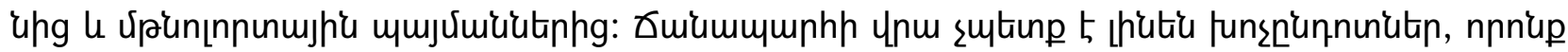

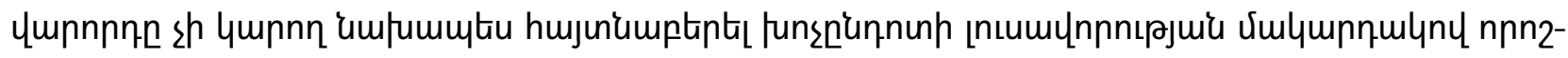

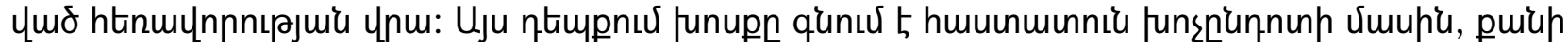

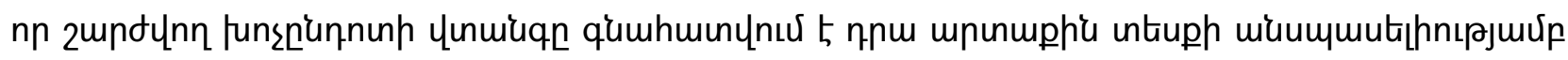

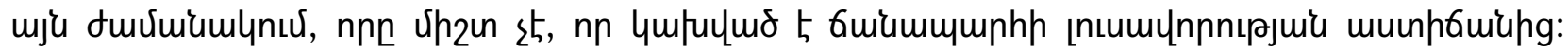

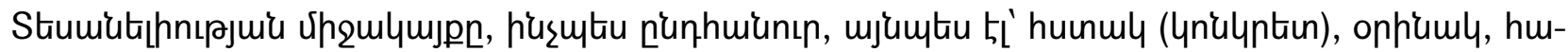

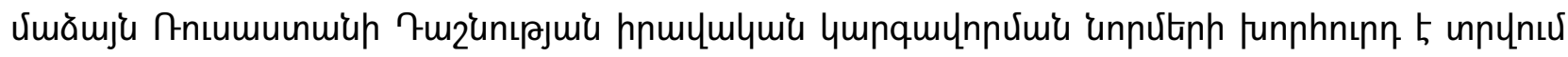

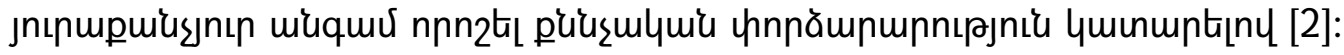

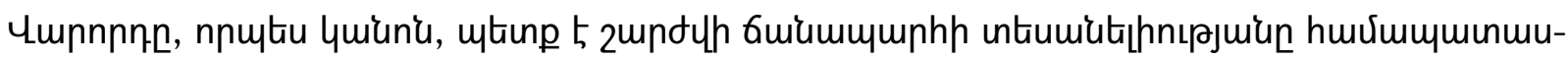

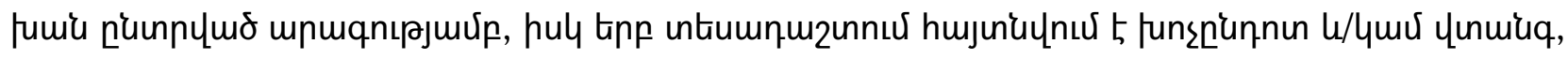

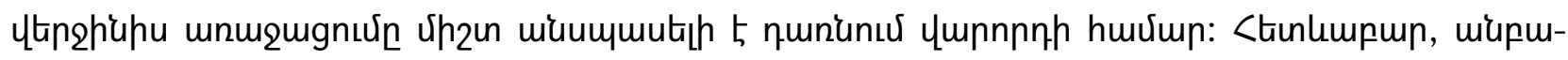

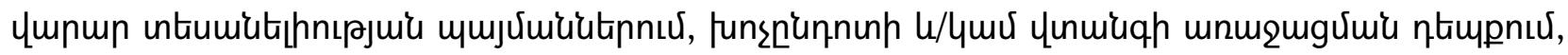

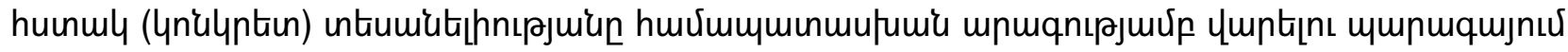

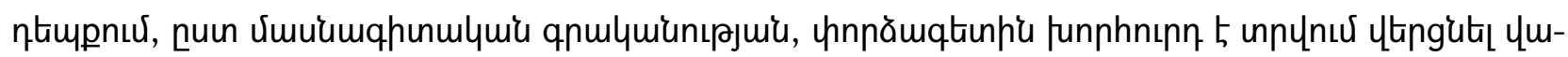

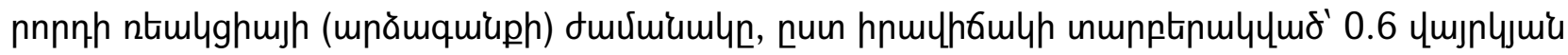

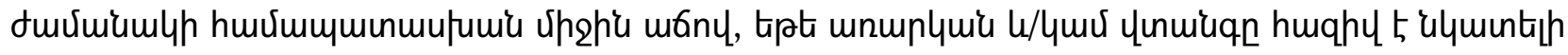

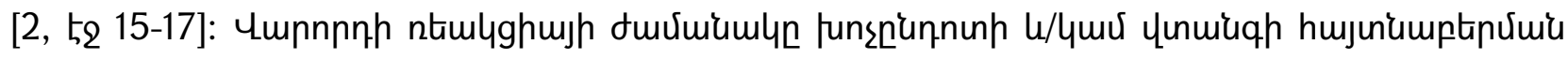

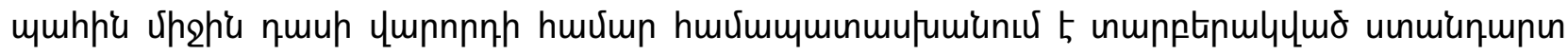

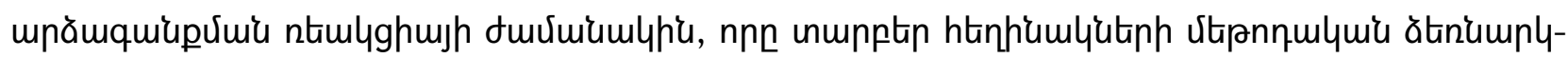
utpnnuर hm24mply

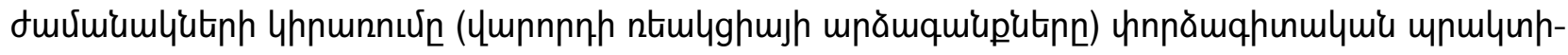

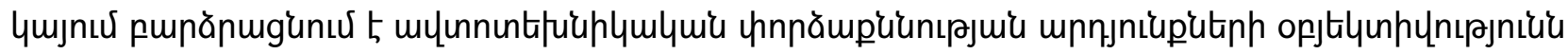

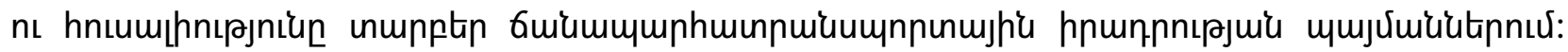

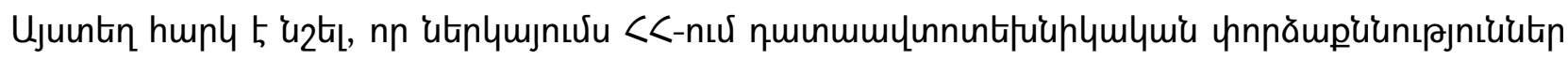

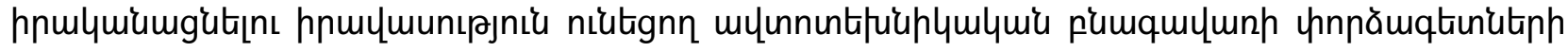

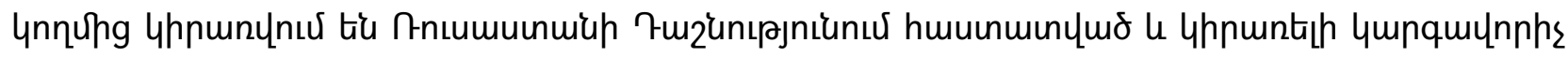

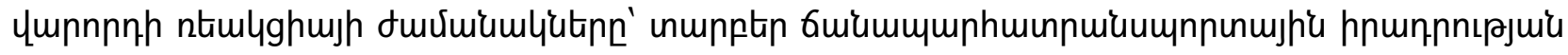




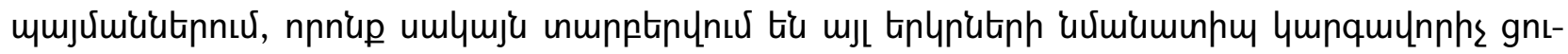

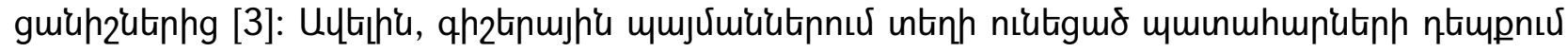

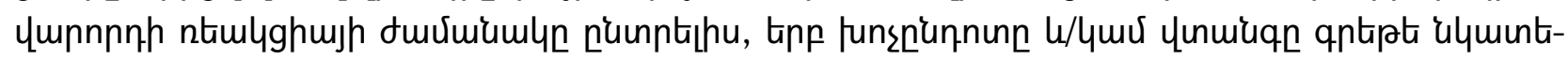

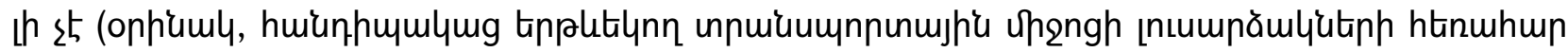

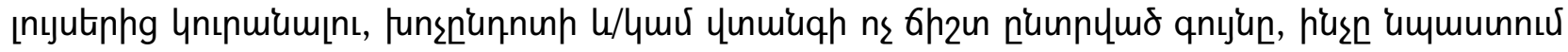

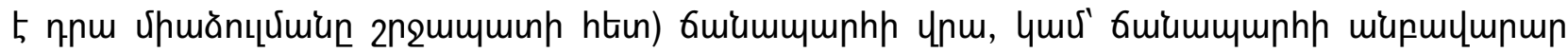

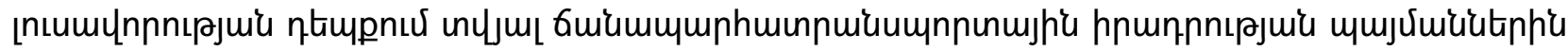

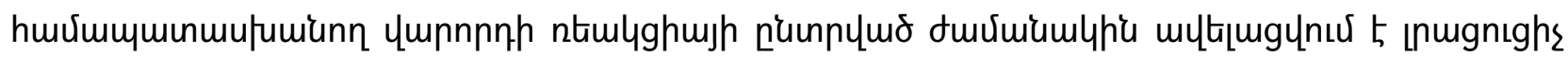

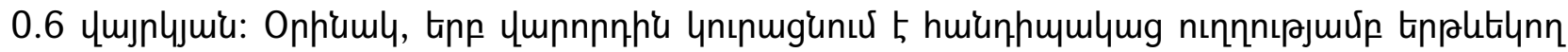

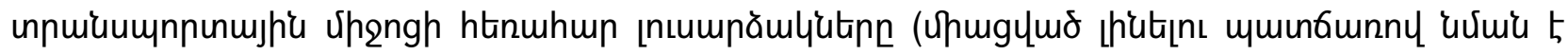

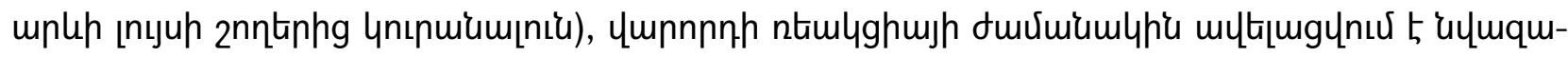

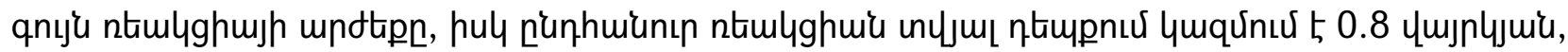

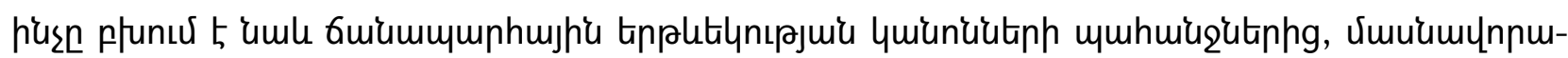

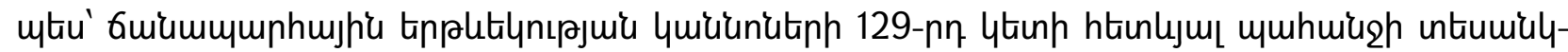

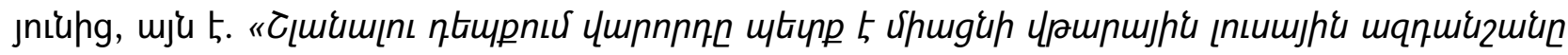

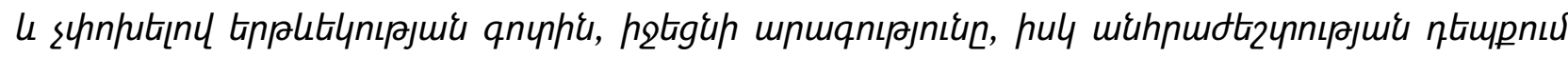
чuikqup» [4, 129-nn 4tin]:

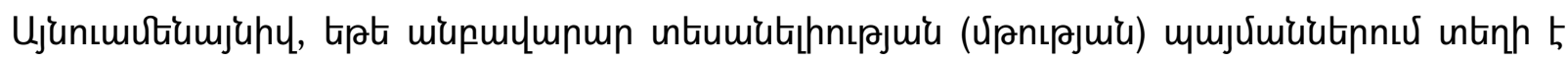

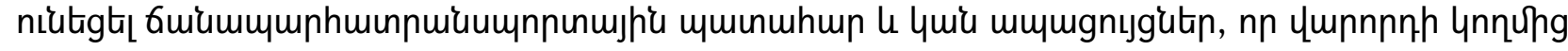

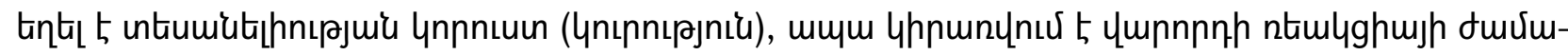

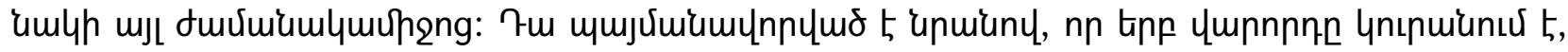

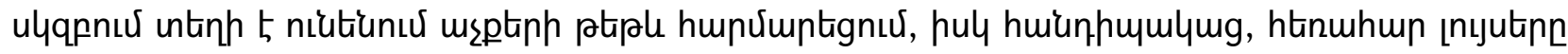

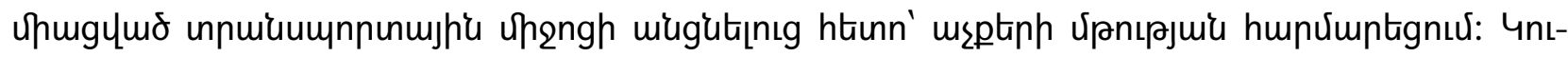

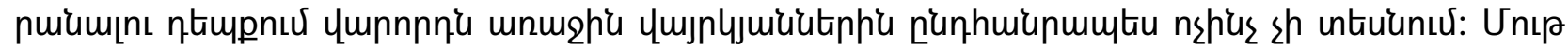

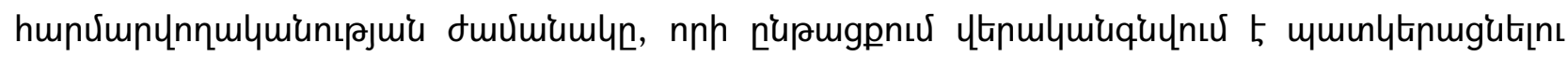

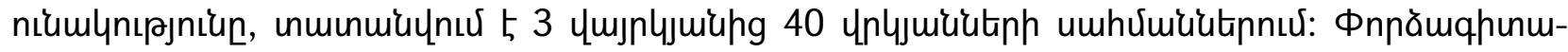

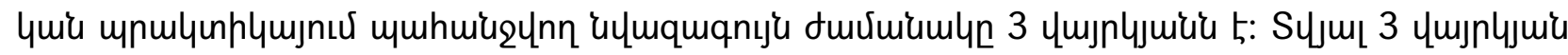

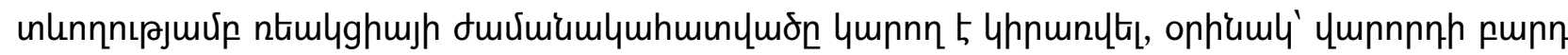

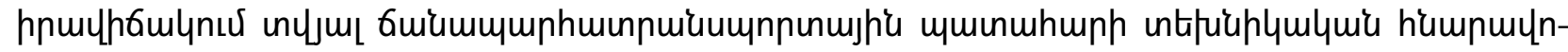

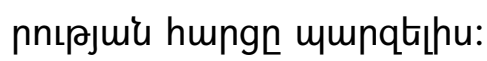

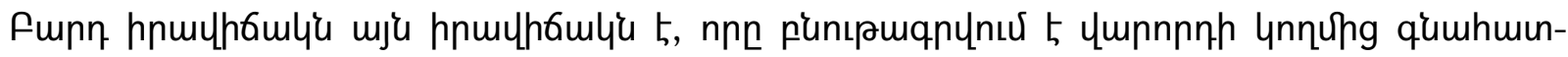

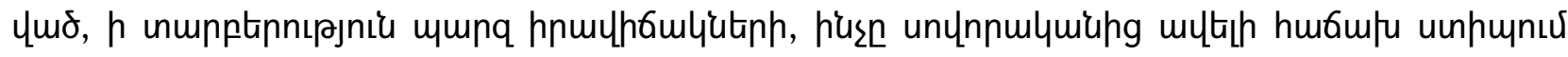

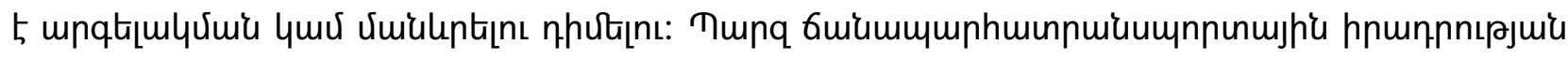

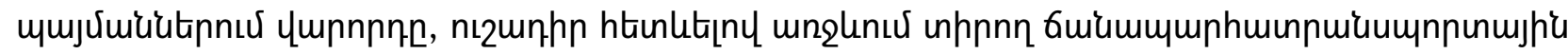

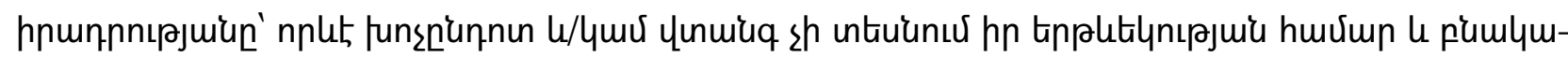

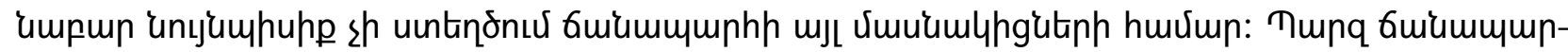

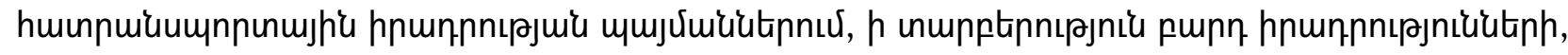

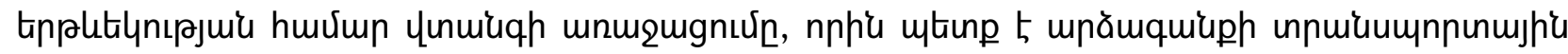

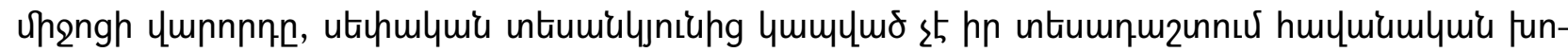

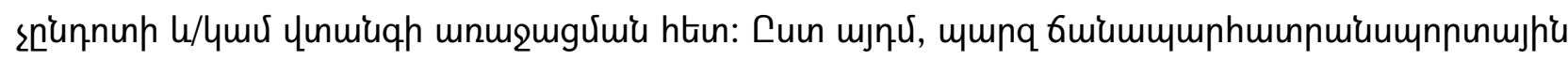

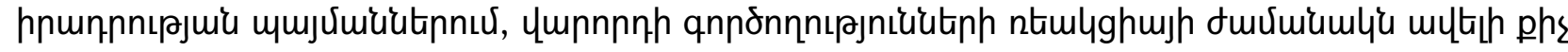

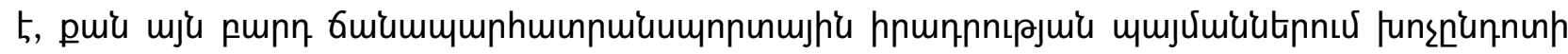

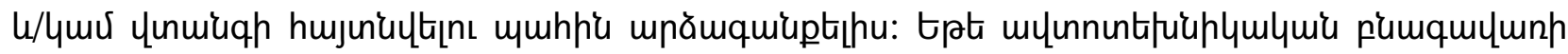




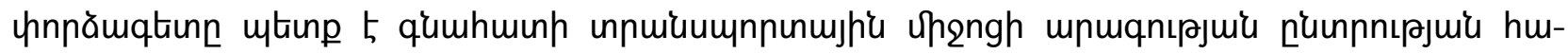

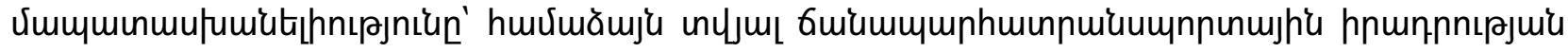

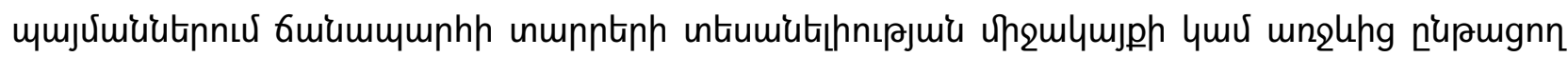

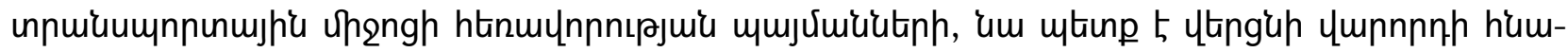

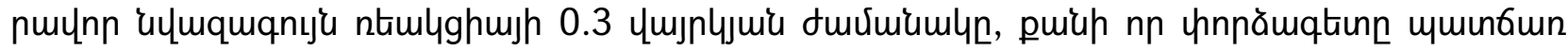

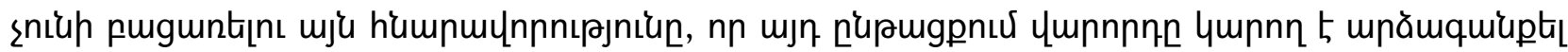

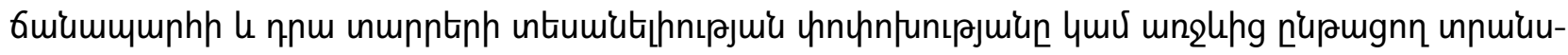

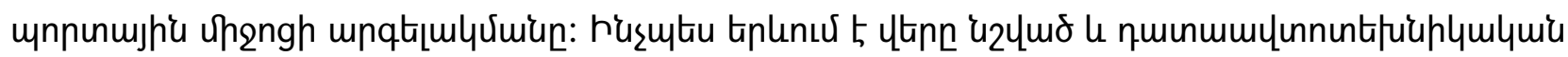

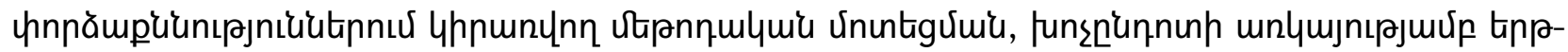

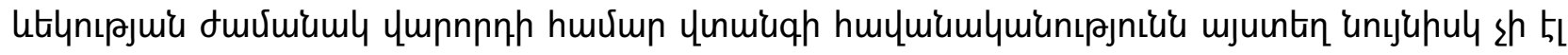

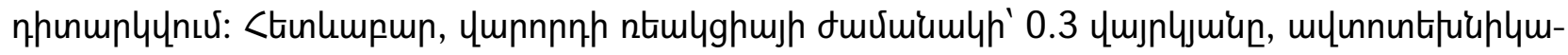

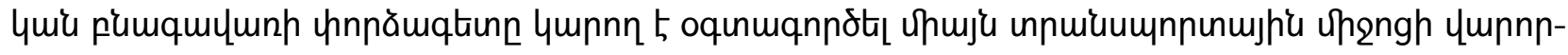

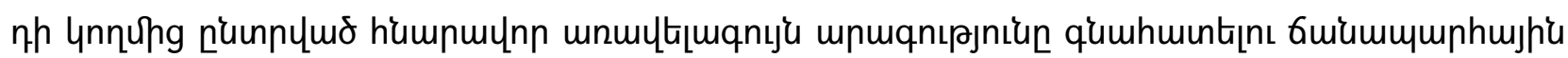

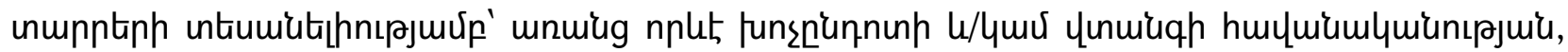

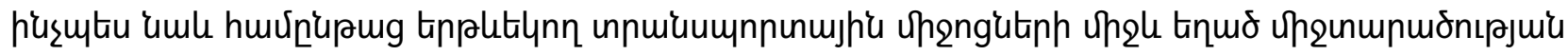

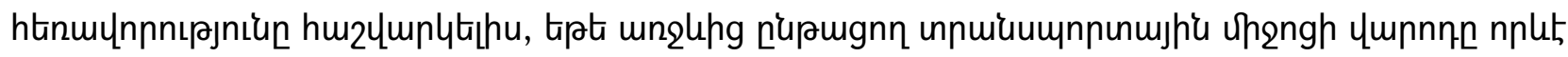

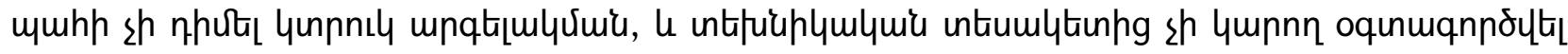

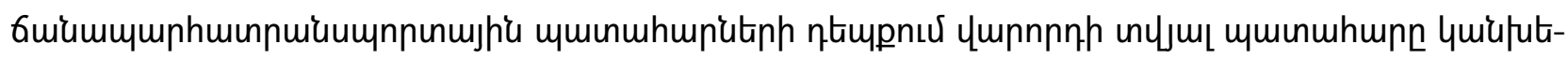

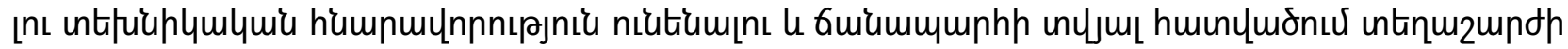

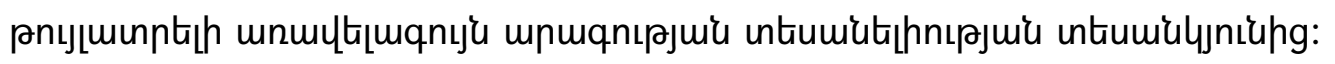

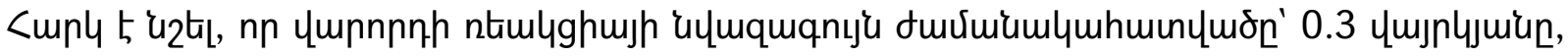

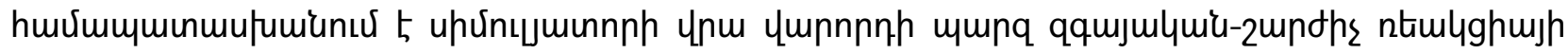

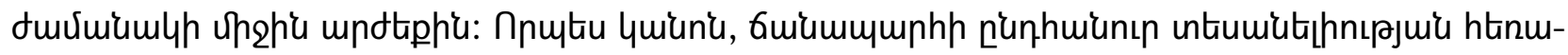

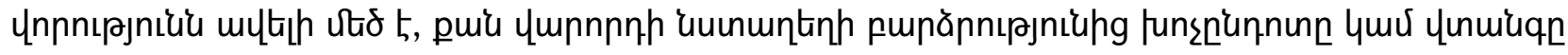

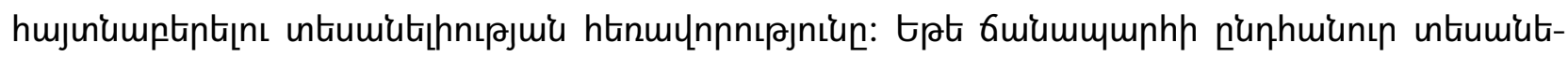

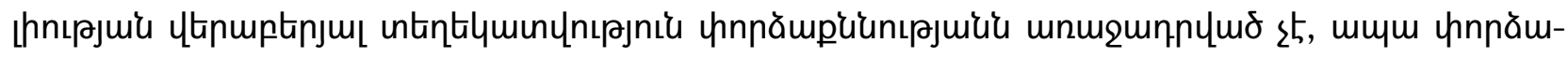

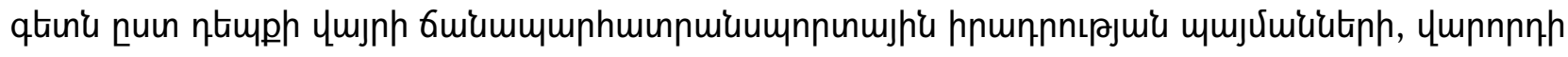

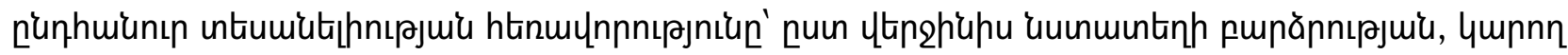

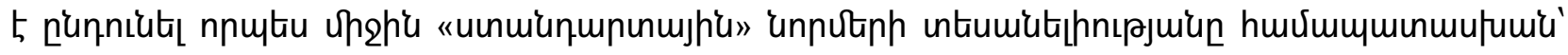

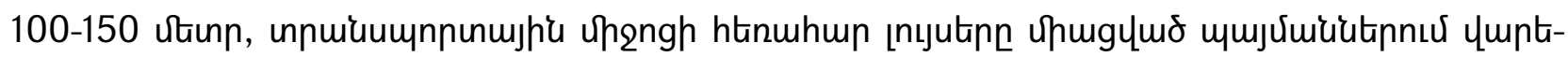

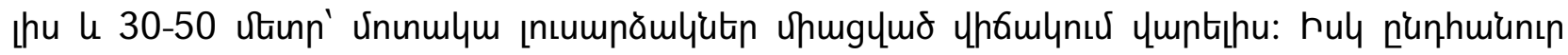

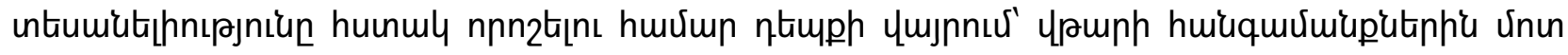

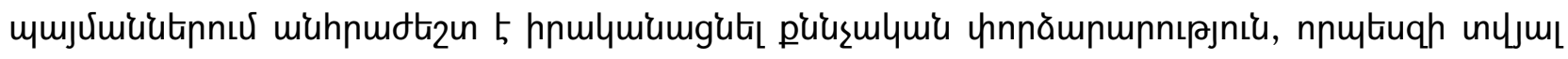

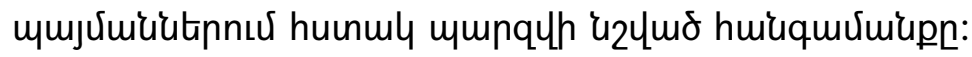

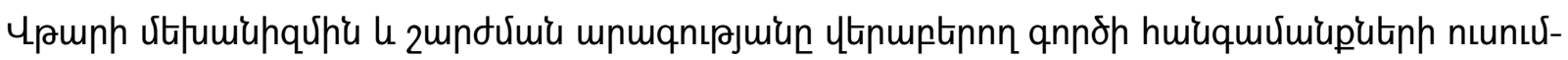

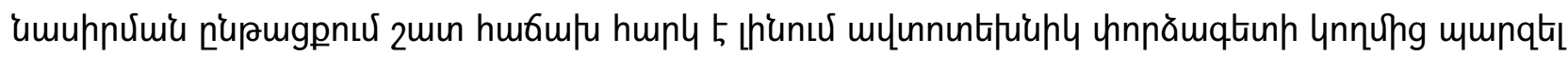

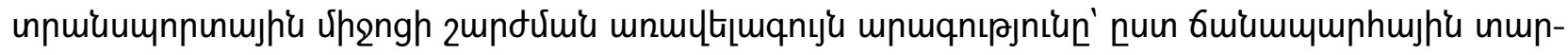

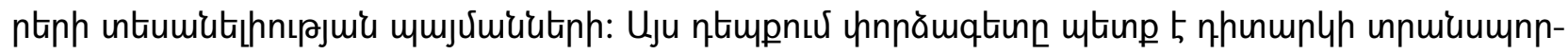

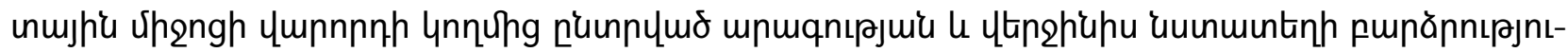

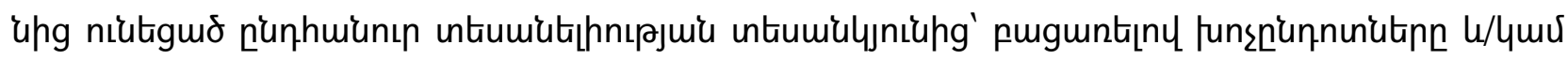

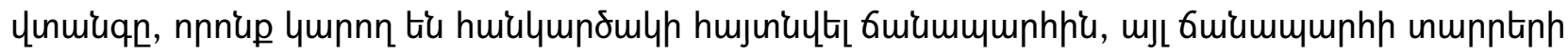

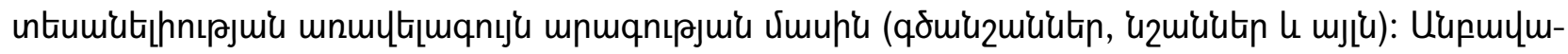

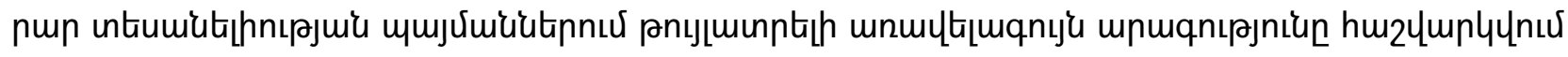




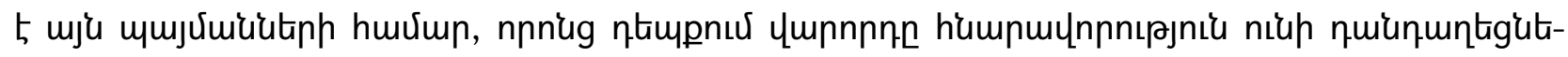

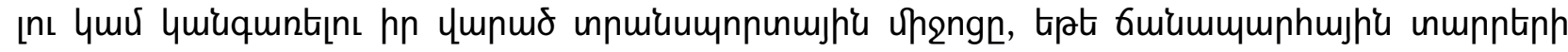

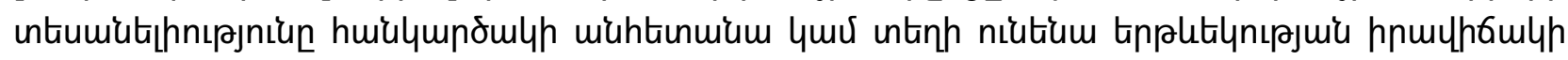

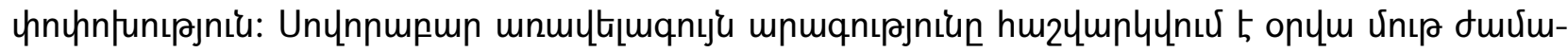

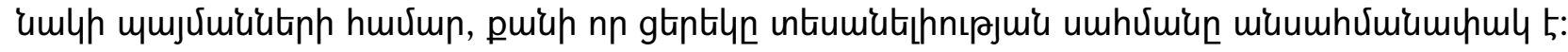

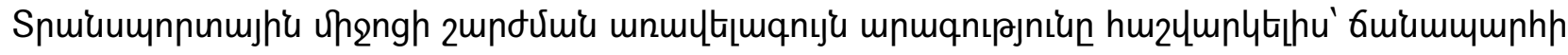

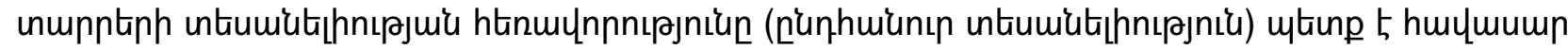

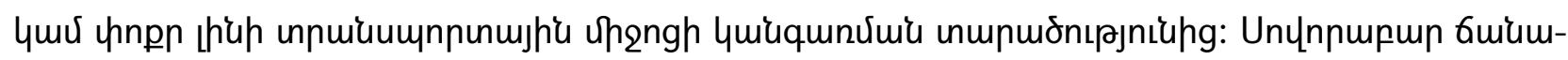

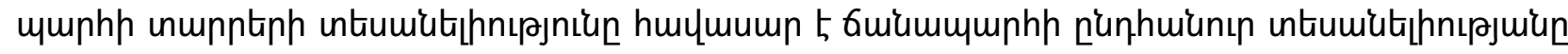

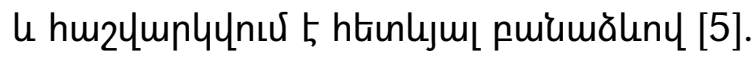

$$
\begin{gathered}
\mathrm{V}_{V D}=3,6 \cdot \mathrm{j}_{a} \cdot T\left[\sqrt{\frac{2 \cdot \mathrm{S}_{V D}}{\mathrm{j}_{a} \cdot T^{2}}+1}-1\right] \\
\mathrm{T}=\mathrm{t}_{1}+\mathrm{t}_{2}+0,5 \cdot \mathrm{t}_{3} \text { ไnl.., }
\end{gathered}
$$

npuntin'

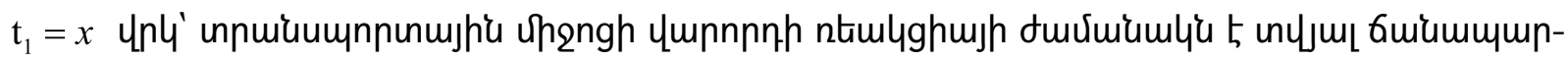

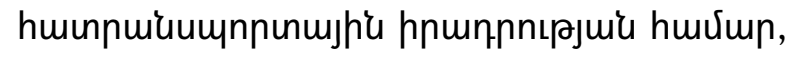

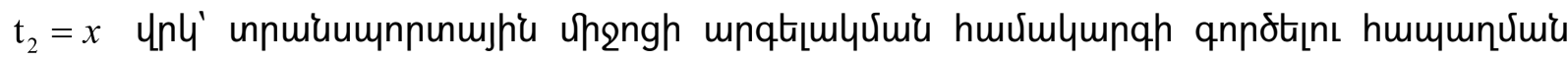
duviumuly 5 ,

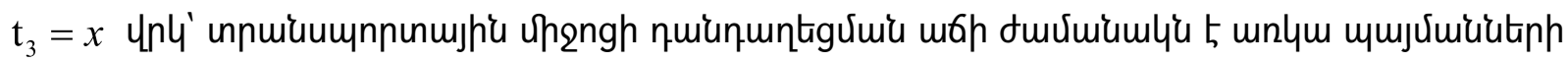
huvium,

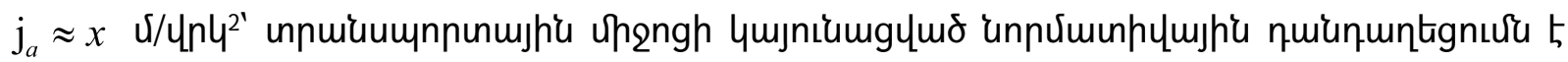

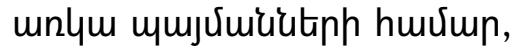

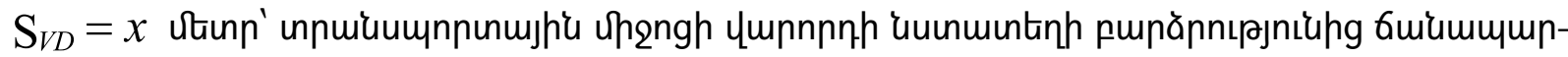

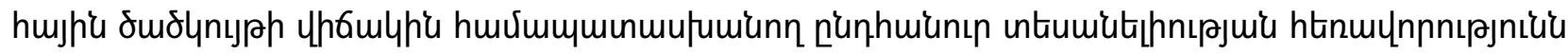
5' mpunuhujuny uro uliunntinny:

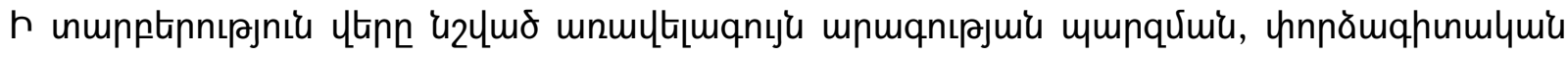

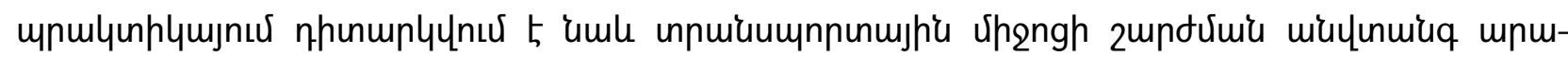

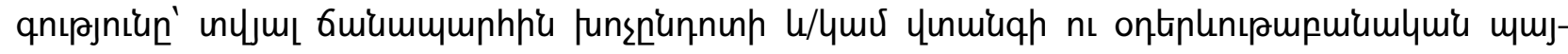

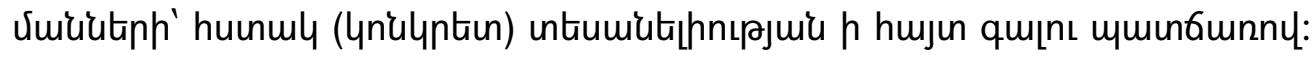

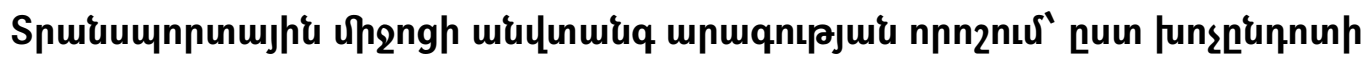

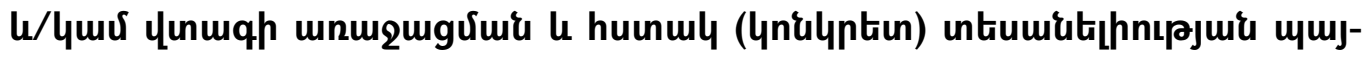 viuuktinp:}

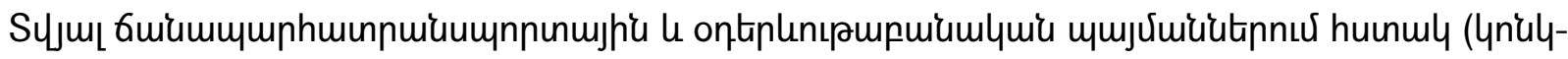

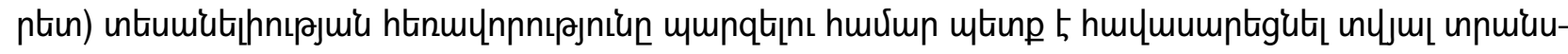

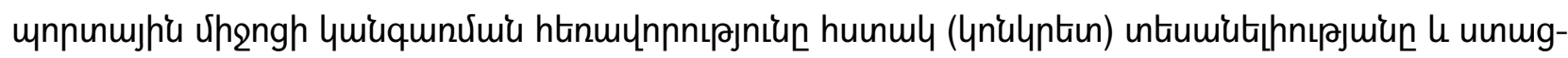
ц 


$$
\begin{gathered}
\mathrm{V}_{\text {bez.konkr.vid }}=-T \cdot \mathrm{j}+\sqrt{(T \cdot j)^{2}+2 j \mathrm{~S}_{\text {vid.konkret }}} \\
\mathrm{T}=\mathrm{t}_{1}+\mathrm{t}_{2}+0,5 \cdot \mathrm{t}_{3}
\end{gathered}
$$

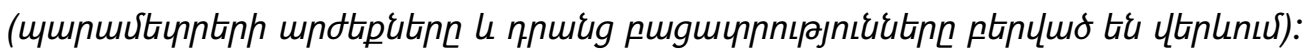

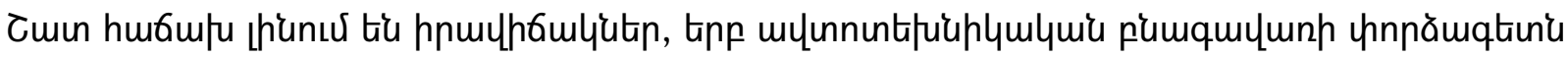

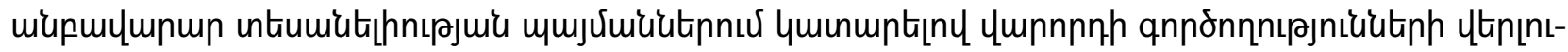

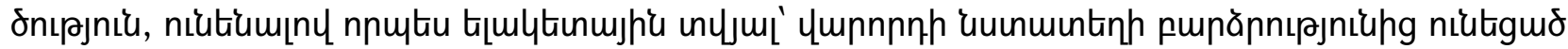

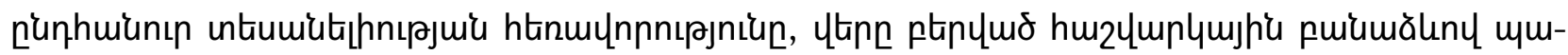

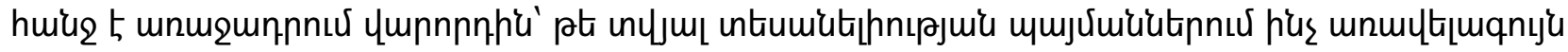

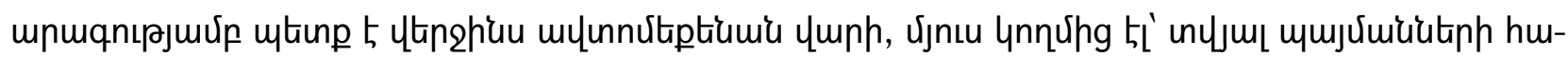

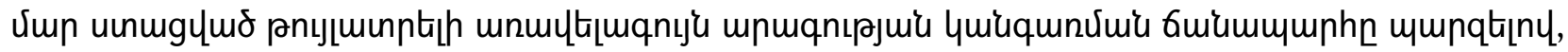

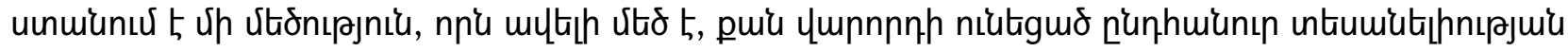

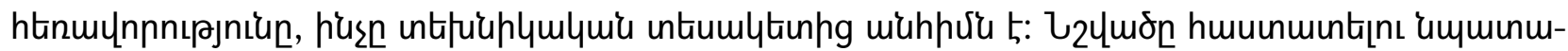

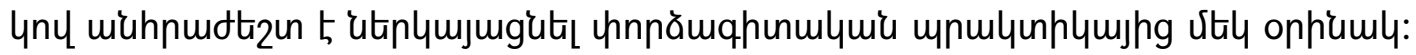

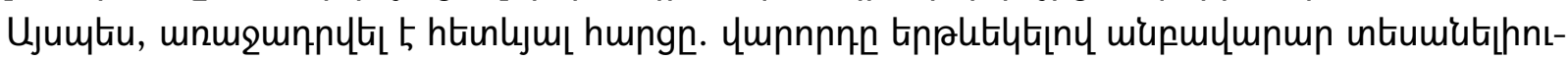

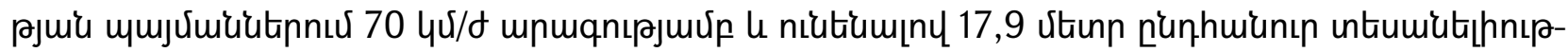

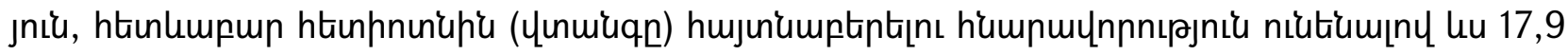

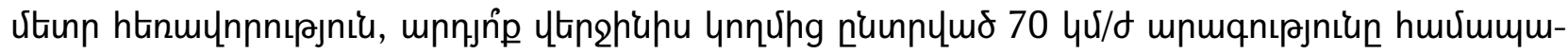

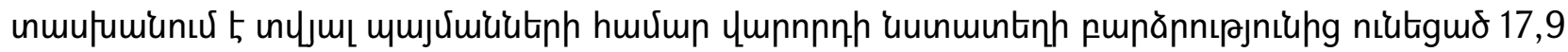
vitunn nunhuiunın untumutignıpjuiun:

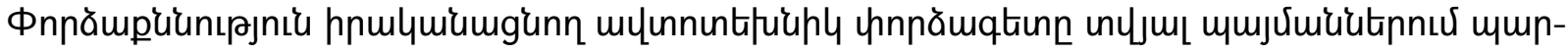

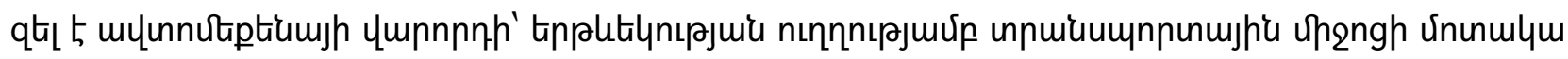

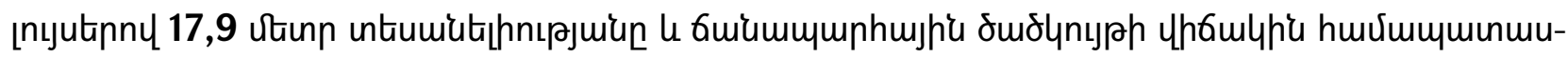

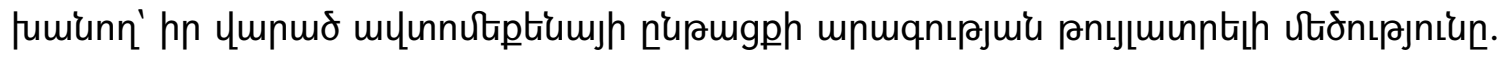

$$
\begin{gathered}
\mathrm{V}_{W D}=3,6 \cdot \mathrm{j}_{a} \cdot T\left|\sqrt{\frac{2 \cdot \mathrm{S}_{W D}}{\mathrm{j}_{a} \cdot T^{2}}+1}-1\right|=3,6 \cdot 1,3 \cdot 0,45 \cdot\left|\sqrt{\frac{2 \cdot 17,9}{1,3 \cdot 0,45^{2}}+1}-1\right| \approx 22,5 \mathrm{lu} \tilde{\mathrm{u}} / \mathrm{d}, \\
\mathrm{T}=\mathrm{t}_{1}+\mathrm{t}_{2}+0,5 \cdot \mathrm{t}_{3}=0,3+0,1+0,5 \cdot 0,1=0,45 \quad \text { पnl. } . \\
\alpha=\operatorname{arctg} \frac{\mathrm{i}}{100}=\operatorname{arctg} \frac{6,55 \div 6,89}{100} \approx 3,75 \div 3,94^{\circ},
\end{gathered}
$$

$\underset{\text { npuntan }}{j_{a}^{\prime}}=j \cdot \cos \alpha-g \cdot \sin \alpha=2 \cdot \cos \left(3,75^{\circ} \div 3,94^{\circ}\right)-9.81 \cdot \sin \left(3,75^{\circ} \div 3,94^{\circ}\right) \approx 1,3 \quad \mathrm{u} / \mathrm{un} \mathrm{u}^{2}$

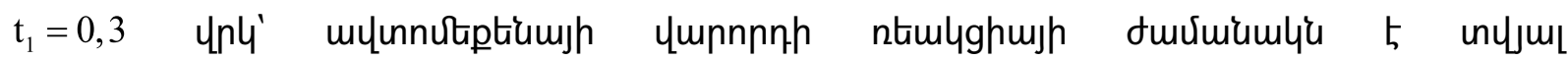

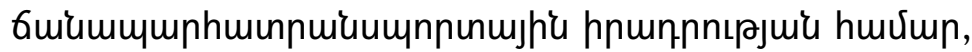

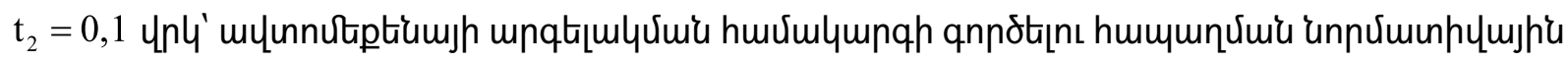
duviuiumlit 5 ,

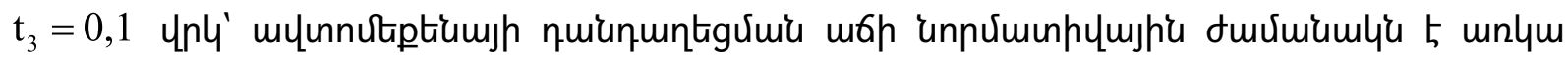


umujưuiutinp huvium,

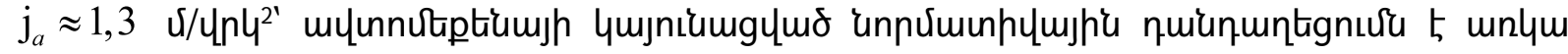
umjưuiutiph huर्ump:

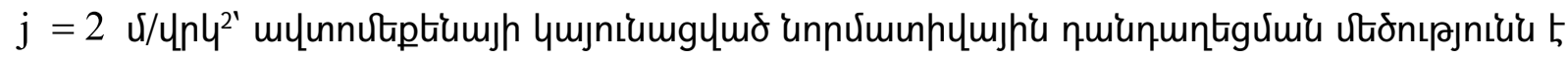

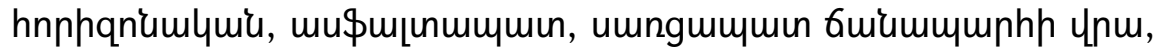

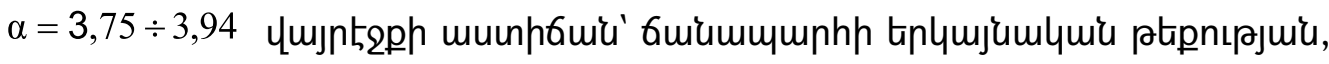

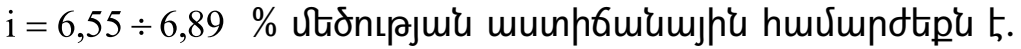

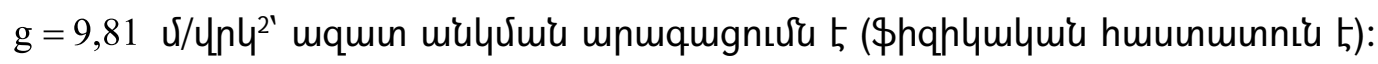

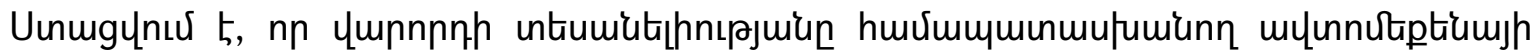

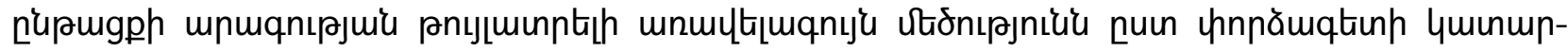

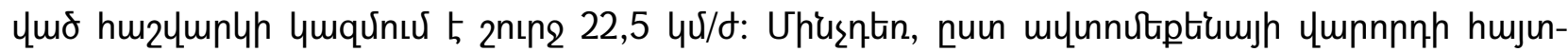

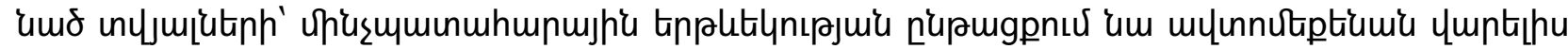

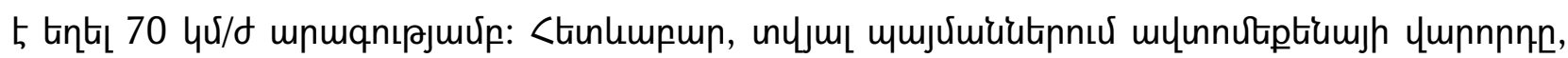

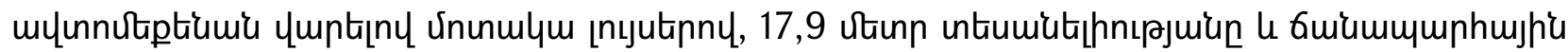

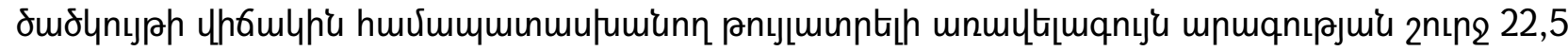

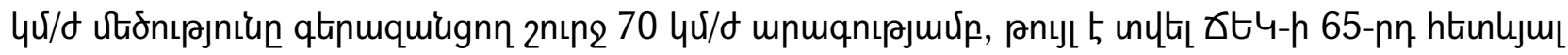

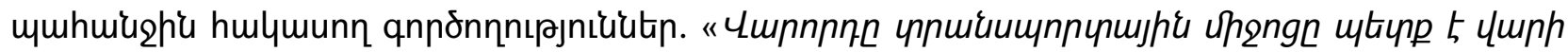

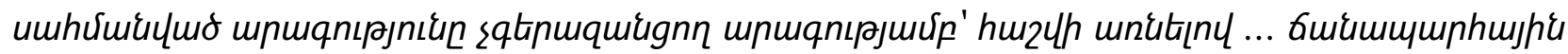

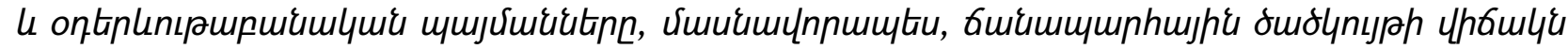

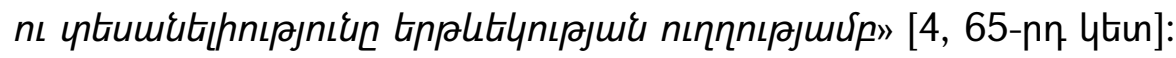

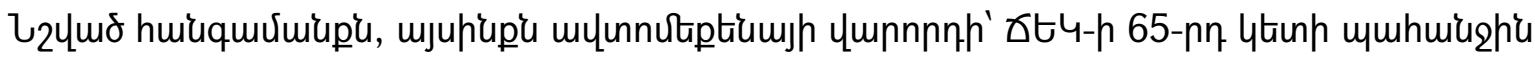

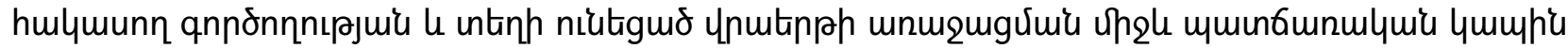

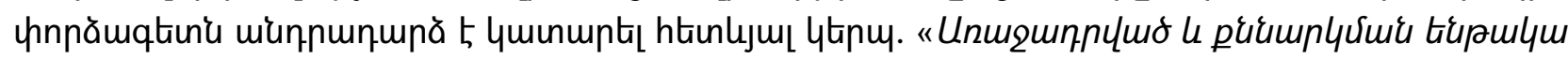

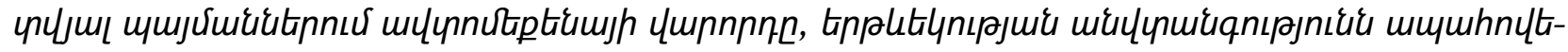

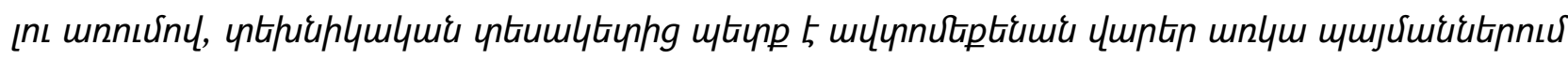

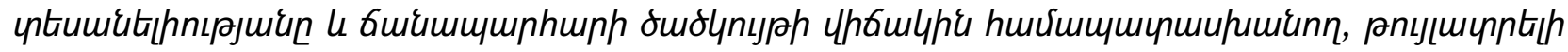

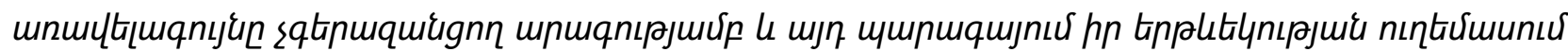

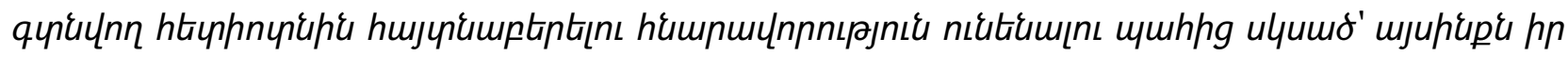

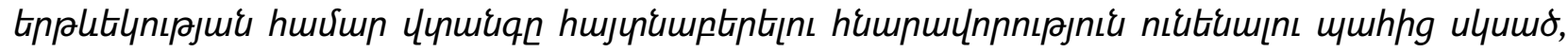

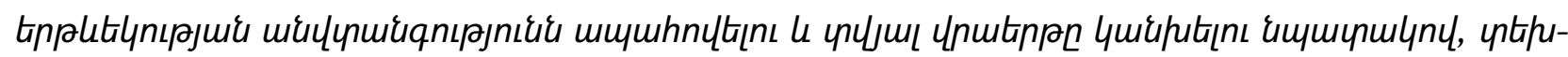

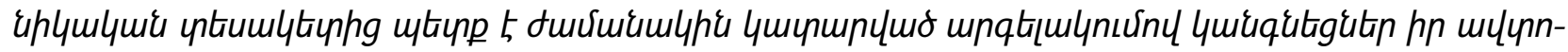

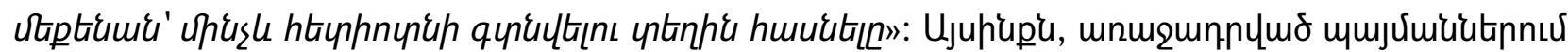

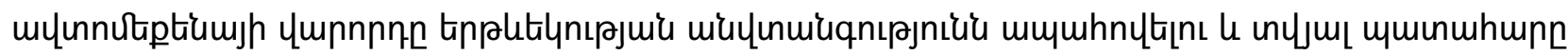

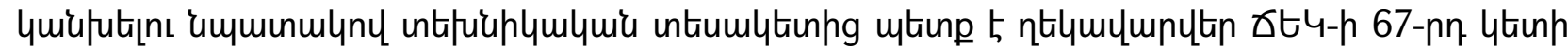

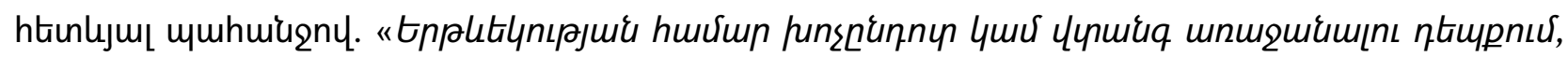

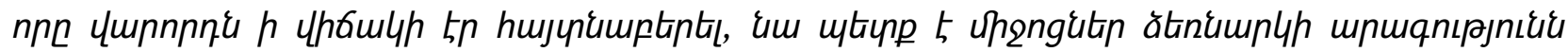

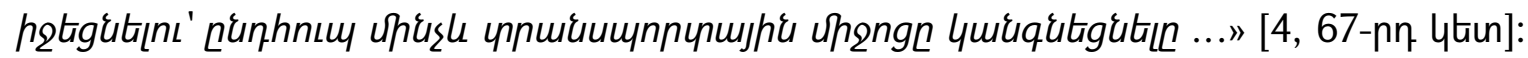

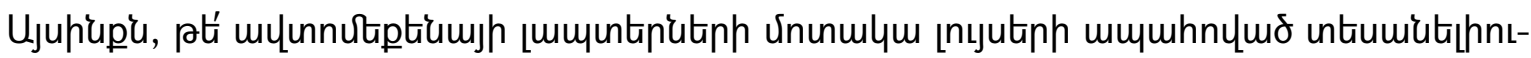

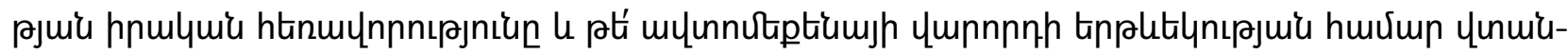

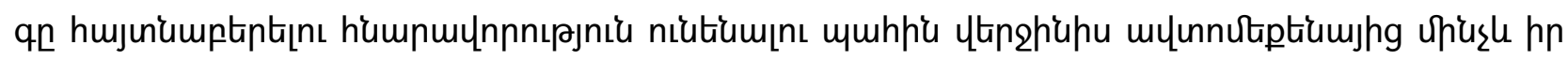

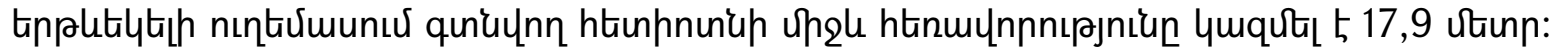

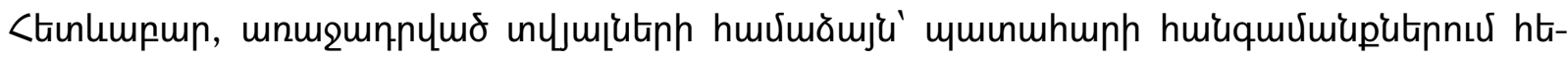

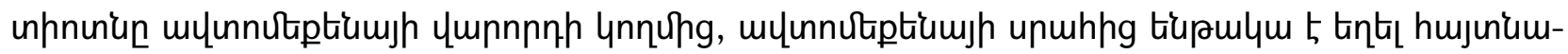




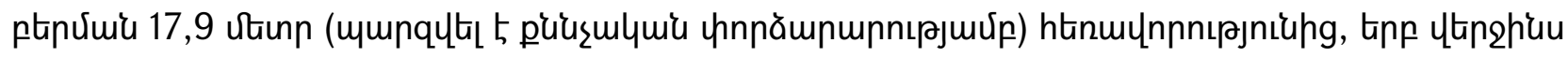

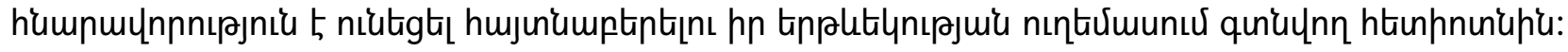

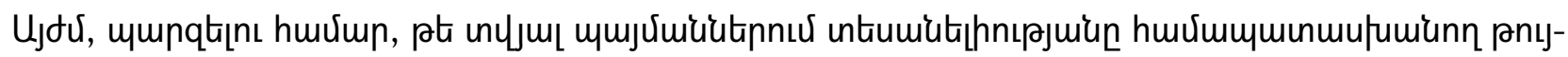

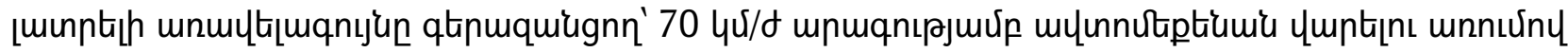

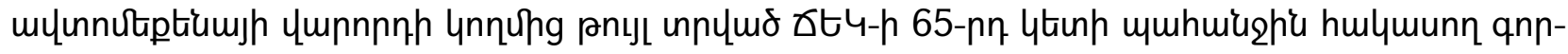

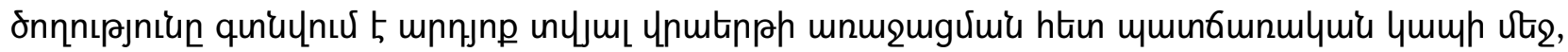

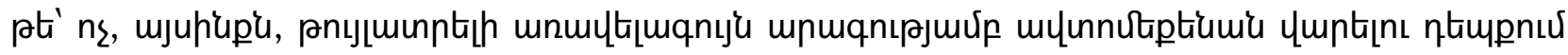

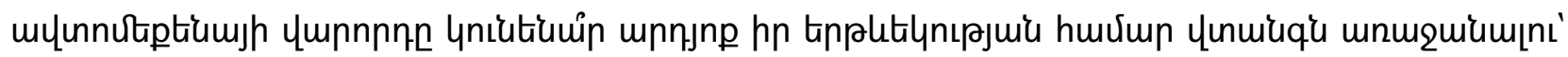

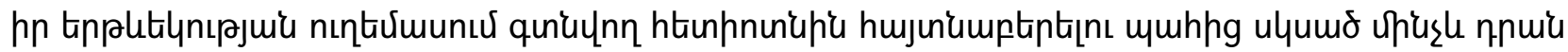

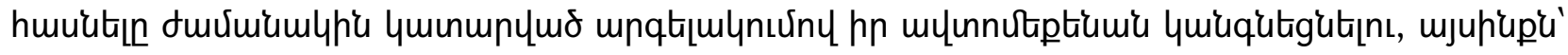

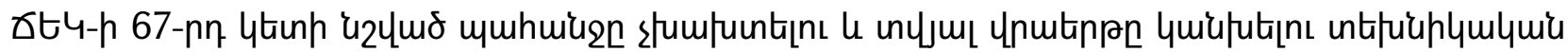

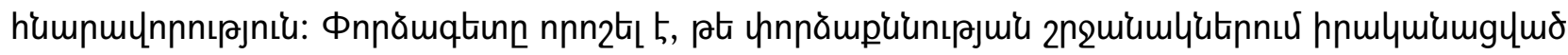

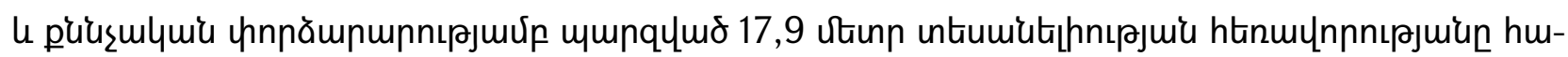

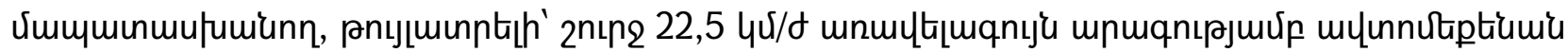

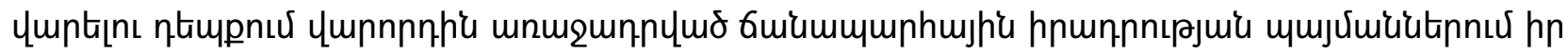

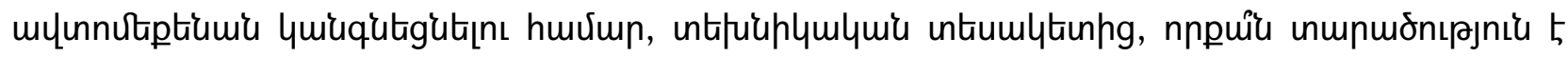
wiuhnuoftizun tintil [5].

$$
\mathrm{S}_{\mathrm{o}}=\left(\mathrm{t}_{1}+\mathrm{t}_{2}+0,5 \cdot \mathrm{t}_{3}\right) \cdot \frac{V_{V D}}{3,6}+\frac{V_{V D}^{2}}{26 \cdot \mathrm{j}_{a}}=(1,2+0,1+0,5 \cdot 0,1) \cdot \frac{22,5}{3,6}+\frac{22,5^{2}}{26 \cdot 1,3} \approx 23,4 \mathrm{u},
$$

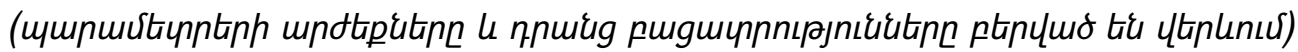

nnunti'

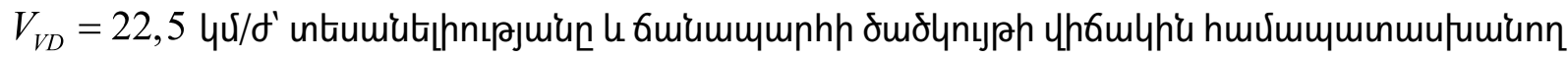

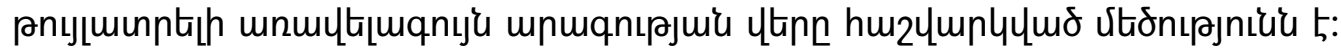

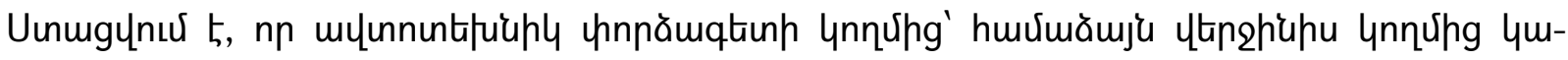

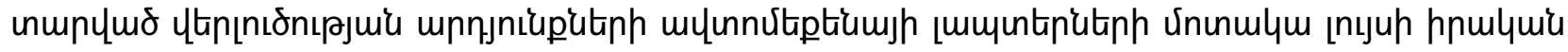

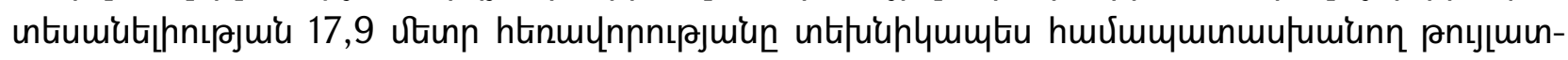

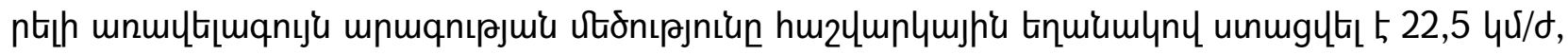

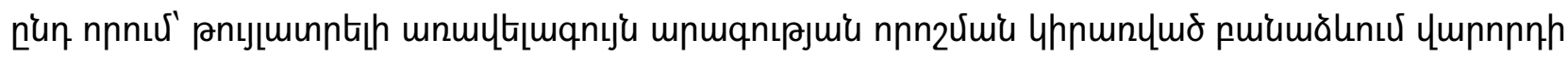

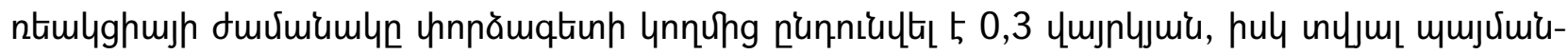

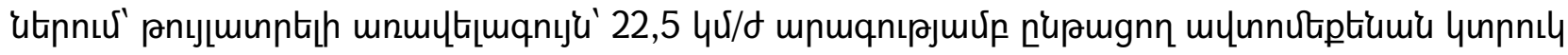

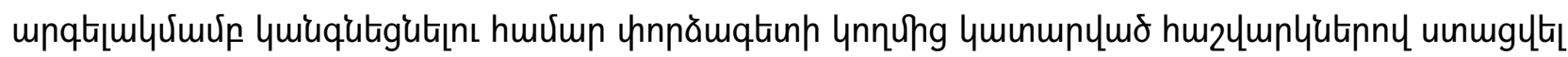

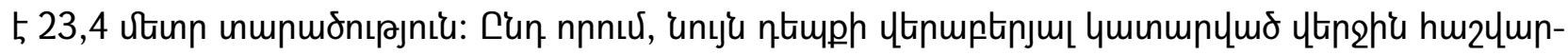

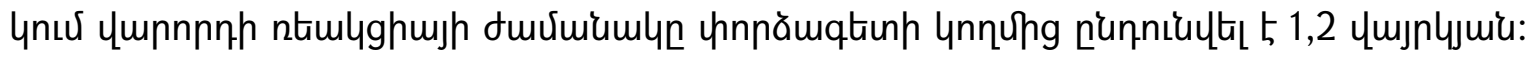

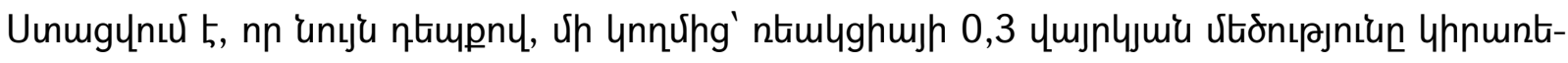

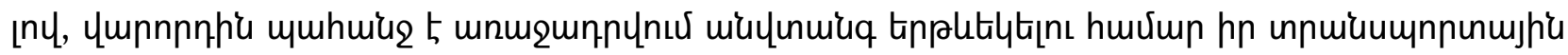

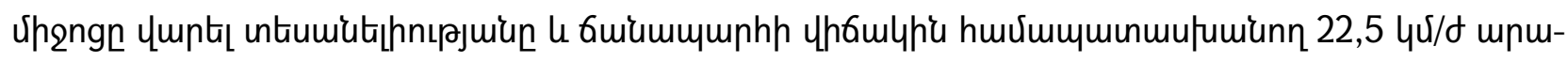

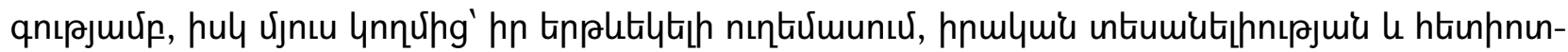

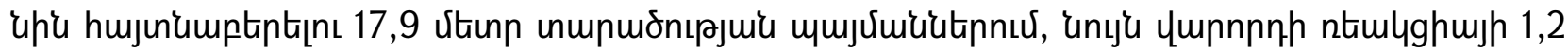

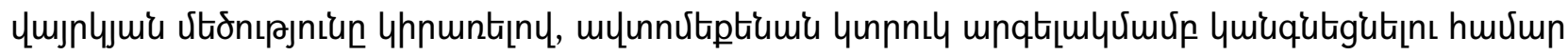

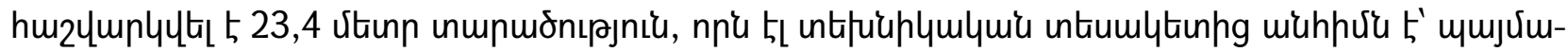

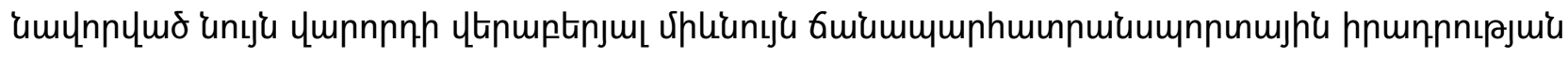




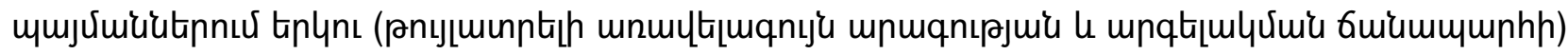

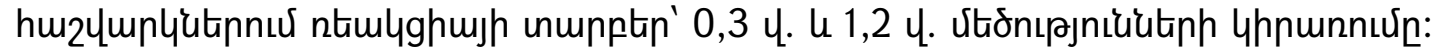

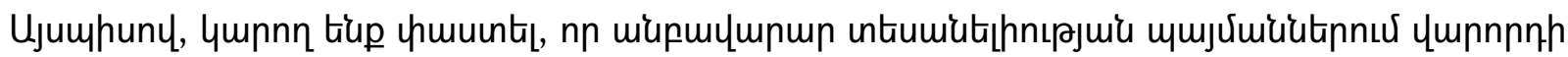

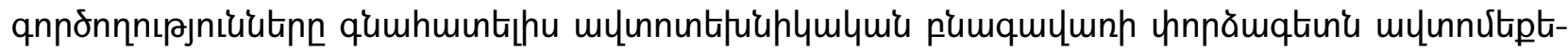

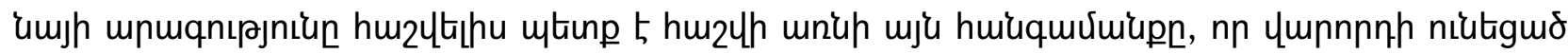

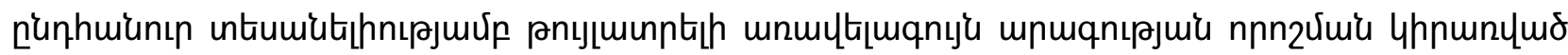

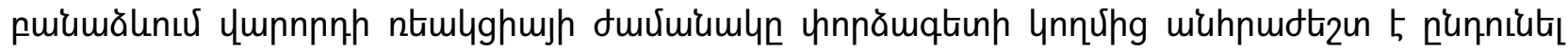

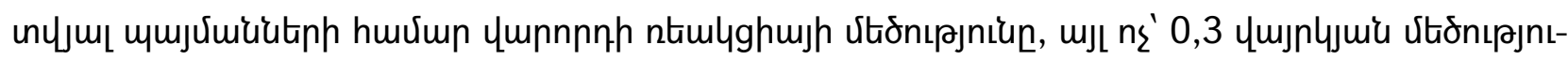

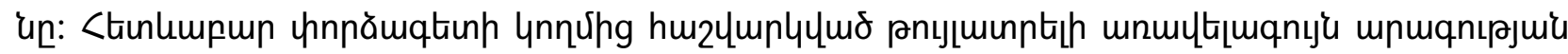

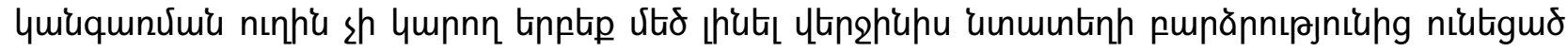

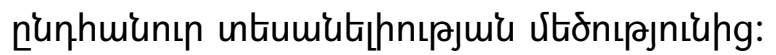

\section{9pulumunıpjuí guily}

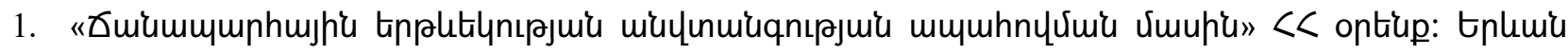
2019p.:

2. Тишин Б.М. «Автотехническая экспертиза: справочно-методическое пособие по производству судебных экспертиз», М.: Инфа-Инженерия, 2018.-252 с.

3. «Вопросы организации производства судебных экспертиз в экспертно-криминалистических подразделениях органов внутренних дел Российской Федерации», приказ МВД России от 29 июня 2005 г. No 511.

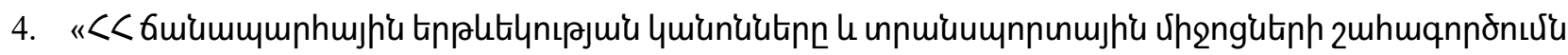

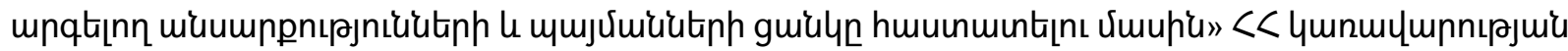
28 hniupup 2007p. № 955-乙 nnn2nıu (ujunıhtin б

5. Пучкин В.А., «Основы экспертного анализа дорожно-транспортных происшествий База данных. Экспертная техника. Методы решений», Ростов-на-Дону 2010г.

\section{АНАЛИЗ И ОЦЕНКА ОСОБЕННОСТЕЙ ДЕЙСТВИЙ ВОДИТЕЛЕЙ АВТОТРАНСПОРТНЫХ СРЕДСТВ ПРИ НАЕЗДАХ НА ПЕШЕХОДОВ В УСЛОВИЯХ ВЛИЯНИЯ ФАКТОРА ОГРАНИЧЕННОЙ ВИДИМОСТИ}

\section{Даллакян Д.А.}

В статье исследуются методологические подходы, реализуемые при проведении судебных автотранспортно-технических экспертиз в действующих экспертных организациях Республики Армения, с точки зрения анализа и оченки особенностей действий водителей, которые зачастую приводят к ошибочным экспертным заключениям.

В данной статье проанализированы некоторые методологические подходы проведения прикладных исследований в области судебных автотранспортно-технических экспертиз, с челью предоставления экспертным, следственным и судебным органам корректного руководства с точки зрения толкования и понимания правил дорожного движения. Также, в соответствии с имеющимися исходными данными и для того, чтобы проверить точность выбранного сравнительного метода по изучению полученных результатов исследований, проведены анализ и оценка особенностей действий водителей автотранспортных средств 
при наездах на пешеходов в условиях влияния фактора ограниченной видимости.

Ключевые слова: судебная автотранспортно-техническая экспертиза, общая видимость, недостаточная видимость, следственный эксперимент, наезд, дорожно-транспортное происшествие.

\section{ANALYSIS AND EVALUATION OF PECULIARITIES OF ACTIONS OF DRIVERS OF VEHICLES IN PEDESTRIAN ACCIDENTS IN POOR VISIBILITY CONDITIONS}

\section{Dallakyan. D.}

The article examines the methodological approaches implemented in carrying out forensic autotechnical expertise in existing expert organizations in the Republic of Armenia, from the point of view of analyzing and assessing the features of the actions of drivers, which often lead to erroneous expert conclusions.

This article provides an analysis of some methodological approaches to applied research in the field of forensic auto-technical expertise, with the aim of providing expert, investigative and judicial bodies with correct guidance in terms of interpretation and understanding of traffic rules. Also, in accordance with the available initial data and in order to verify the accuracy of the chosen comparative method for studying the obtained research results, an analysis and assessment of the features of the actions of vehicle drivers when colliding with pedestrians were carried out in the context of the influence of the factor of poor visibility.

Key words: forensic auto-technical expertise, general visibility, poor visibility, road accide 